\title{
Plasma inflammatory biomarkers response to aerobic versus resisted exercise training for chronic obstructive pulmonary disease patients.
}

\author{
Shehab M. Abd El-Kader ${ }^{1}$, Osama H. Al-Jiffri' ${ }^{2}$, Fadwa M. Al-Shreef ${ }^{2}$
}

1. Department of Physical Therapy, Faculty of Applied Medical Sciences, King Abdulaziz University.

2. Department of Medical Laboratory Technology, Faculty of Applied Medical Sciences, King Abdulaziz University.

\begin{abstract}
Background: Chronic obstructive pulmonary disease (COPD) is a main risk for morbidity, associated with alterations in systemic inflammation. Recent studies proved that morbidity and mortality of COPD is related to systemic inflammation as it contributes to the pathogenesis of atherosclerosis and cardiovascular disease. However, increase of inflammatory cytokines adversely affects quality of life, alteration in ventilatory and skeletal muscles functions. Moreover, exercise training has many beneficial effects in correction of the adverse effects of COPD.

Objective: This study aimed to compare the response of inflammatory cytokines of COPD to aerobic versus resisted exercises. Materials and methods: One hundred COPD diseased patients participated in this study and were randomly included in two groups; the first group received aerobic exercise, whereas the second group received resisted exercise training for 12 weeks.

Results: The mean values of TNF- $\alpha$, Il-2, IL-4, IL-6 and CRP were significantly decreased in both groups. Also; there was a significant difference between both groups at the end of the study with more reduction in patients who received aerobic exercise training.

Conclusion: Aerobic exercise is more appropriate than resisted exercise training in modulating inflammatory cytokines level in patients with chronic obstructive pulmonary disease.

Keywords: Aerobic exercise, chronic obstructive pulmonary disease, inflammatory cytokines, resisted exercises.

DOI: http://dx.doi.org/10.4314/ahs.v16i2.19

Cite as: Abd El-Kader SM, Al-Jiffri OH, Al-Shreef FM. Plasma inflammatory biomarkers response to aerobic versus resisted exercise training for chronic obstructive pulmonary disease patients. Afri Health Sci 2016;16(2): 507-515. http://dx.doi.org/10.4314/abs. v16i2.19
\end{abstract}

\section{Introduction}

Globally, chronic obstructive pulmonary disease (COPD) becomes more prevalent and becomes the third cause of death ${ }^{1,2}$. However, by 2030 it is expected to have about 9 million patients to die due to COPD every year ${ }^{3}$. Moreover, the economic and health related burdens of COPD are enormous ${ }^{4}$.

Recently, studies proved that morbidity and mortality of COPD is related to systemic inflammation ${ }^{5}$ as it contributes to the pathogenesis of atherosclerosis and cardiovascular disease ${ }^{6}$. Moreover, increase of inflammatory

\section{Corresponding author:}

Shehab M. Abd El-Kader,

Department of Physical Therapy,

Faculty of Applied Medical Sciences,

King Abdulaziz University,

P.O. Box 80324, Jeddah, 21589,Saudi Arabia.

E.mail: salmuzain@kau.edu.sa cytokines adversely affects quality of life, alteration in ventilator and skeletal muscles functions ${ }^{7-12}$.

The adverse effects of COPD are not limited to the respiratory system, but have many systemic adverse effects. Pulmonary rehabilitation has a vital role for management of the de-conditioning effects of systemic inflammation and other pathological features of COPD as exercise intolerance and poor quality of life $\mathrm{e}^{13,14}$.

Exercise training has many beneficial effects in correction of the adverse effects $\mathrm{COPD}^{15,16}$. In healthy subjects, exercises were proved to improve immune system response $^{17}$. Even low intensity exercise training was found to modulate the elevated level of systemic inflammation in patients with systemic inflammation ${ }^{18}$. However, poor quality of life and exercise intolerance can be modulated by exercise training in chronic obstructive pulmonary disease patients ${ }^{16}$.

As the ideal exercise intensity that efficiently modulates the elevated inflammatory cytokines is inconclusive, this

African Health Sciences Vol 16 Issue 2, June 2016 
study was designed to compare the impact of aerobic versus resisted exercises on inflammatory cytokines in chronic obstructive pulmonary disease patients.

\section{Patients and methods}

\section{Subjects}

One hundred chronic obstructive pulmonary disease patients participated in this study; their age ranged from 35 to 55 years and was selected from the Internal Medicine Department at King Abdul Aziz University hospital and other hospitals at Jeddah area. Exclusion criteria included smokers, cardiovascular disorders, alcohol abuse problems, hepatitis and renal diseases. Participants were randomly assigned into 2 groups; group (A) received aerobic exercise training for 3 months and group (B) received resisted exercise training. The original sample consisted of 178 participants who underwent the eligibility assessment. In the enrollment phase, 50 of them were excluded as they didn't meet inclusion criteria and 13 refused to participate, then the randomization was done.

This substudy thus included 115 subjects (58 patients in group (A) received aerobic exercise training and $57 \mathrm{pa}-$ tients in group (B) received resisted exercise training). During the follow up, in group (A) 5 patients discontinued intervention ( 2 patients disliked the diet regimen, 2 patients had work related schedule problems and $1 \mathrm{pa}-$ tient discontinued due to unknown reasons) and in the group (B) 4 patients discontinued intervention (3 patients had work related schedule problems and 1 patient discontinued due to unknown reasons).In addition, 3 patients in group (A) and 3 patients in group (B) were excluded from the analysis due to insufficient blood samples. The Scientific Research Ethical Committee, Faculty of Applied Medical Sciences at King Abdulaziz University, approved this study. All participants signed the consent form before enrollment in the study.

\section{Measurements}

Blood samples were drained from the antecubital vein after a 12 -h fasting, the blood samples were centrifuged at $4^{\circ} \mathrm{C}(1000=\mathrm{g}$ for $10 \mathrm{~min})$. Interleukin-2 (IL-2) Interleukin-4 (IL-4), Interleukin-6 (IL-6) levels were analyzed by "Immulite 2000" immunassay analyzer (Siemens Healthcare Diagnostics, Deerfield, USA). However, tumor necrosis factor- alpha $(\mathrm{TNF}-\alpha)$ and $\mathrm{C}$-reactive protein (CRP) levels were measured by ELISA kits (ELX 50) in

African Health Sciences Vol 16 Issue 2, June 2016 addition to ELISA microplate reader (ELX 808; BioTek Instruments, USA). Measurements of TNF- $\alpha$, Il-2, IL-4, IL- 6 and CRP were taken before starting of the study (pre-test) and after 12 weeks (post-test).

\section{Procedures}

Following the previous evaluation ,all participants were randomly assigned into two groups:

1. Group (A) participated in a treadmill aerobic exercise (Enraf Nonium, Model display panel Standard, NR 1475.801, Holand) which was conducted according to recommendation of aerobic exercise application approved by the American College of Sports Medicine ${ }^{19}$. Training program included five minutes for warming up in the form of range motion and stretching exercises, thirty minutes of aerobic exercise training ( $60-70 \%$ of maximum heart rate) and five minutes of cooling down (on treadmill with low speed and without inclination). Participants had three sessions / week for 3 months with close supervision of a physical therapist.

2. Group (B) participated in the resistance exercises on some resistance gym machines (Nautilus Sports/Medical Industries, Independence, VA). The work load was approximately $70 \%$ to $85 \%$ of one resistance maximum (1-RM), as suggested by the recommendations of the American College of Sports Medicine (ACSM, 2002), with weekly load adjustments ${ }^{20}$. The execution of physical exercises prioritized the major muscle groups followed by the smaller ones in terms of leg extension, hamstring curl, bench press with free weights, pulldown, pronation grip, arm curl with free weights, triceps extension with curl bar in the pulley, horizontal leg press, sit-ups, side elevation and calf. For abdominal exercises and calf three sets of 15 repetitions were prescribed during the entire experimental period. Resistance training (RT) was conducted in three weekly sessions, on alternating days and with the duration of approximately $60 \mathrm{~min} /$ session for 3 months. The volunteers were supervised by a physical therapist during the entire experimental period, on a maximum of 3 volunteers per physical therapist.

\section{Statistical analysis}

The mean values of the investigated parameters obtained before and after three months in both groups were compared using paired " $t$ " test. Independent " $t$ " test was used for the comparison between the two groups $(\mathrm{P}<0.05)$. 


\section{Results}

The baseline characteristics of all participants are shown in Table (1). Most participants (61\%) were men. Forty participants were assigned to the aerobic exercise group
( $\mathrm{n}=40 ; 25$ males and 15 females), while the resistance exercise group ( $n=40 ; 24$ males and 16 females). None of the baseline characteristics differed significantly between the two groups is listed in table (1).

\section{Table (1): Mean value of baseline and demographic data for participants in both groups:}

\begin{tabular}{|l|l|l|l|}
\hline & \multicolumn{2}{|l|}{ Mean +SD } & Significance \\
\cline { 2 - 4 } & $\begin{array}{l}\text { Aerobic exercise } \\
\text { group }\end{array}$ & $\begin{array}{l}\text { Resistance } \\
\text { exercise group }\end{array}$ & \\
\hline Age $($ year $)$ & $34.17 \pm 6.25$ & $36.14 \pm 4.79$ & $\mathrm{P}>0.05$ \\
\hline $\begin{array}{l}\text { Gender } \\
\text { ratio }(\mathrm{male} / \mathrm{female})\end{array}$ & $25 / 15$ & $24 / 16$ & $\mathrm{P}>0.05$ \\
\hline Weight $(\mathrm{kg})$ & $61.31 \pm 5.42$ & $58.92 \pm 7.53$ & $\mathrm{P}>0.05$ \\
\hline Height $(\mathrm{cm})$ & $160.27 \pm 9.35$ & $159.14 \pm 8.63$ & $\mathrm{P}>0.05$ \\
\hline BMI $\left(\mathrm{kg} / \mathrm{m}^{2}\right)$ & $21.53 \pm 1.81$ & $20.93 \pm 1.72$ & $\mathrm{P}>0.05$ \\
\hline TNF- $\boldsymbol{\alpha}(\mathrm{pg} / \mathrm{ml})$ & $6.13 \pm 1.52$ & $5.84 \pm 1.71$ & $\mathrm{P}>0.05$ \\
\hline IL-2 $(\mathrm{pg} / \mathrm{ml})$ & $8.10 \pm 2.34$ & $7.91 \pm 2.48$ & $\mathrm{P}>0.05$ \\
\hline IL-4 $(\mathrm{pg} / \mathrm{ml})$ & $5.83 \pm 1.57$ & $5.72 \pm 1.65$ & $\mathrm{P}>0.05$ \\
\hline IL-6 $(\mathrm{pg} / \mathrm{ml})$ & $8.32 \pm 2.36$ & $8.16 \pm 2.21$ & $\mathrm{P}>0.05$ \\
\hline CRP $(\mathrm{mg} / \mathrm{dl})$ & $15.12 \pm 3.48$ & $14.95 \pm 3.36$ & $\mathrm{P}>0.05$ \\
\hline FVC $(\mathrm{L})$ & $2.41 \pm 0.76$ & $2.29 \pm 0.65$ & $\mathrm{P}>0.05$ \\
\hline FEV $(\mathrm{L})$ & $1.38 \pm 0.57$ & $1.14 \pm 0.48$ & $\mathrm{P}>0.05$ \\
\hline FEV $/$ FVC $(\%)$ & $47.15 \pm 8.14$ & $45.82 \pm 9.12$ & $\mathrm{P}>0.05$ \\
\hline MVV $(\mathrm{L} / \mathrm{minute})$ & $46.34 \pm 10.18$ & $43.25 \pm 11.23$ & $\mathrm{P}>0.05$ \\
\hline
\end{tabular}

BMI = Body mass index; TNF- $\alpha$ : tumor necrosis factor - alpha; IL-2: Interleukin-2; IL-4: Interleukin-4; IL-6: Interleukin-6; CRP: C-reactive protein; $\mathrm{FVC}=$ forced vital capacity; $\mathrm{FEV}_{1}=$ forced expiratory volume in the first second; $\mathrm{FEV}_{1} / \mathrm{FVC}=$ Ratio between forced expiratory volume in the first second and forced vital capacity; $\mathrm{FEF}_{25-75}=$ forced expiratory flow during the middle half of the FVC maneuver; MVV = Maximum voluntary ventilation.

The mean value of TNF- $\alpha$, IL-2, IL-4, IL-6 and CRP were significantly lower in both groups after treatments (Table $2 \& 3$ ). There were significant differences between mean levels of the investigated parameters in group (A) and group (B) after treatment (Table 3) with more reduc- tion in patients received aerobic exercise training. These results confirm that aerobic exercise is more appropriate than resisted exercise training in modulating inflammatory cytokines level of chronic obstructive pulmonary disease patients. 
Table (2): Mean value and significance of TNF- $\alpha$, IL-2, IL-4, IL-6 and CRP in group (A) before and after treatment.

\begin{tabular}{|l|l|l|l|l|}
\hline & \multicolumn{2}{|l|}{ Mean +SD } & \multirow{2}{*}{ T- value } & \multirow{2}{*}{ Significance } \\
\cline { 2 - 3 } & Before & After & & \\
\hline TNF- $\boldsymbol{\alpha}(\mathrm{pg} / \mathrm{ml})$ & $6.13 \pm 1.52^{*}$ & $4.25 \pm 1.43$ & 6.83 & $\mathrm{P}<0.05$ \\
\hline IL-2 $(\mathrm{pg} / \mathrm{ml})$ & $8.10 \pm 2.34^{*}$ & $4.61 \pm 1.92$ & 7.64 & $\mathrm{P}<0.05$ \\
\hline IL-4 $(\mathrm{pg} / \mathrm{ml})$ & $5.83 \pm 1.57^{*}$ & $3.57 \pm 1.41$ & 6.91 & $\mathrm{P}<0.05$ \\
\hline IL-6 $(\mathrm{pg} / \mathrm{ml})$ & $8.32 \pm 2.36^{*}$ & $5.16 \pm 1.97$ & 7.32 & $\mathrm{P}<0.05$ \\
\hline CRP $(\mathrm{mg} / \mathrm{dl})$ & $15.12 \pm 3.48^{*}$ & $8.93 \pm 3.16$ & 8.21 & $\mathrm{P}<0.05$ \\
\hline
\end{tabular}

TNF- $\alpha$ : tumor necrosis factor - alpha; IL-2: Interleukin-2; IL-4: Interleukin-4; IL-6: Interleukin-6; CRP: C-reactive protein; $(*)$ indicates a significant difference between the two groups, $\mathrm{P}<0.05$.

Table (3): Mean value and significance of TNF- $\alpha$, IL-6, IL-8 and CRP in group (B) before and after treatment.

\begin{tabular}{|l|l|l|l|l|}
\hline & \multicolumn{2}{|l|}{ Mean +SD } & \multirow{2}{*}{ T- value } & \multirow{2}{*}{ Significance } \\
\cline { 2 - 4 } & Before & After & & \\
\hline TNF- $\alpha(\mathrm{pg} / \mathrm{ml})$ & $5.84 \pm 1.71^{*}$ & $5.03 \pm 1.52$ & 3.41 & $\mathrm{P}<0.05$ \\
\hline IL-2 $(\mathrm{pg} / \mathrm{ml})$ & $7.91 \pm 2.48^{*}$ & $6.53 \pm 2.15$ & 3.27 & $\mathrm{P}<0.05$ \\
\hline IL-4 $(\mathrm{pg} / \mathrm{ml})$ & $5.72 \pm 1.65^{*}$ & $4.61 \pm 1.38$ & 3.48 & $\mathrm{P}<0.05$ \\
\hline IL-6 $(\mathrm{pg} / \mathrm{ml})$ & $8.16 \pm 2.21^{*}$ & $6.74 \pm 2.15$ & 3.56 & $\mathrm{P}<0.05$ \\
\hline CRP $(\mathrm{mg} / \mathrm{dl})$ & $14.95 \pm 3.36^{*}$ & $11.52 \pm 3.16$ & 4.13 & $\mathrm{P}<0.05$ \\
\hline
\end{tabular}

TNF- $\alpha$ : tumor necrosis factor - alpha; IL-2: Interleukin-2; IL-4: Interleukin-4; IL-6: Interleukin-6; CRP: C-reactive protein, $(*)$ indicates a significant difference between the two groups, $\mathrm{P}<0.05$.

Table (3): Mean value and significance of TNF- $\alpha$, IL-6, IL-8 and CRP in group (A) and group (B) after treatment.

\begin{tabular}{|l|l|l|l|l|}
\hline & \multicolumn{2}{|l|}{ Mean +SD } & T- value & Significance \\
\cline { 2 - 3 } & Group (A) & Group (B) & & \\
\hline TNF- $\alpha(\mathrm{pg} / \mathrm{ml})$ & $4.25 \pm 1.43^{*}$ & $5.03 \pm 1.52$ & 3.46 & $\mathrm{P}<0.05$ \\
\hline IL-2 $(\mathrm{pg} / \mathrm{ml})$ & $4.61 \pm 1.92^{*}$ & $6.53 \pm 2.15$ & 3.72 & $\mathrm{P}<0.05$ \\
\hline IL-4 $(\mathrm{pg} / \mathrm{ml})$ & $3.57 \pm 1.41^{*}$ & $4.61 \pm 1.38$ & 3.41 & $\mathrm{P}<0.05$ \\
\hline IL-6 $(\mathrm{pg} / \mathrm{ml})$ & $5.16 \pm 1.97^{*}$ & $6.74 \pm 2.15$ & 3.52 & $\mathrm{P}<0.05$ \\
\hline CRP $(\mathrm{mg} / \mathrm{dl})$ & $8.93 \pm 3.16^{*}$ & $11.52 \pm 3.16$ & 4.05 & $\mathrm{P}<0.05$ \\
\hline
\end{tabular}

TNF- $\alpha$ : tumor necrosis factor - alpha; IL-2: Interleukin-2; IL-4: Interleukin-4; IL-6: Interleukin-6; CRP: C-reactive protein, $(*)$ indicates a significant difference between the two groups, $\mathrm{P}<0.05$. 


\section{Discussion}

Chronic obstructive pulmonary disease (COPD) is a major cause of chronic morbidity and mortality; it is currently the fourth highest cause of death in the world, and is predicted to be the third leading cause of mortality worldwide by the year $2020^{21,22}$. Inflammation is one of key processes in the pathogenesis of $\mathrm{COPD}^{23,24}$.Chronic obstructive pulmonary disease (COPD) is understood as a systemic inflammation mediated by cigarette smoking and air pollution, and subsequently induced inflammatory cytokines, such as tumor necrosis factor (TNF)- $\alpha$, interleukin (IL)-6, and IL- $8{ }^{25}$. To date, there are relatively few adequately-powered, trials of an exercise intervention on inflammatory biomarkers in individuals with COPD, to the best of our knowledge, this is the first study to compare the response of inflammatory cytokines of COPD to aerobic versus resisted exercises. In our study, the mean values of TNF- $\alpha$, IL-2, IL-4, IL- 6 and CRP were significantly decreased in both groups. Also; there was a significant difference between both groups at the end of the study with more reduction in group (A) who received aerobic exercise training. This means that in chronic obstructive pulmonary disease patients aerobic exercise is more appropriate for modulating inflammatory cytokine levels than is resisted exercise training. These results are in line with many previous studies.

Dekker etal. stated that a 12-week exercise intervention resulted in a significant decrease in circulating IL-6 in subjects with type 2 diabetes mellitus who underwent an exercise program without weight $\operatorname{loss}^{26}$. Also, Mikkelsen etal. proved that life-long endurance exercise was associated with a lower level of the inflammatory markers CRP and IL-6 in elderly subjects ${ }^{27}$. While, Sugawara etal. concluded that the levels of elevated inflammatory cytokines decreased significantly after intervention with an anti-inflammatory nutrition combined with the lowintensity exercise in stable elderly COPD patients ${ }^{28}$. In addition, there is evidence of lowered IL- 6 and TNF- $\alpha$ after prolonged exercise in obese women ${ }^{29}$ and decreased TNF- $\alpha$ after 12 weeks of aerobic exercise in patients with heart disease ${ }^{30}$. Moreover, in obese postmenopausal women with type 2 diabetes, 14 weeks of aerobic exercise decreased CRP by $15 \%$ and marginally decreased IL-6 $(p=0.07)^{31}$. Likewise, 12 weeks of exercise reduced IL-18 levels by $17.5 \%$ in patients with metabolic syndrome ${ }^{32}$. In one of the largest, yet non-randomized, exercise studies conducted to date (HERITAGE Family Study), plasma CRP was significantly reduced with 20 weeks of aerobic training only in the sub-group of persons with a high baseline CRP. The approximate 29\% CRP decrease in this study was not mediated by changes in body weight ${ }^{33}$.

Neto et al. proved that high-intensity exercise training program induced an improvement of biomarkers of inflammation (a reduction of IL-6, TNF- $\alpha$ \& leptin and an increase of interleukin-4 (IL-4) \& interleukin-10 (IL10) thus indicating that exercise has a full anti-inflammatory effect ${ }^{34}$.While, Balducci et al. applied their study on eighty-two patients were randomized into 4 groups: sedentary control (A) received low-intensity aerobic exercise, group (B) performed high-intensity aerobic, group (C) performed aerobic and resistance exercises and group (D) performed exercise (with the same caloric expenditure) for 12 months. Physical exercise in type 2 diabetic patients with metabolic syndrome was associated with a significant reduction of inflammatory biomarkers ${ }^{35}$. Moreover, Brooks et al. stated that a 16-week resistance training intervention reduced CRP and increased adiponectin levels in older adults with type 2 diabetes ${ }^{36}$.

In contrast to the previous studies Rall et al., reported that 12 week of high-intensity progressive resistance strength training does not affect TNF $\alpha$, IL-6, or interleukin-2 (IL-2) production ${ }^{37}$. Also, Rodrigo and colleagues founded that weight-lifting exercises for 6 muscle groups in the upper and lower limbs (2 sets of 8 repetitions each), and the initial load was set at $80 \%$ of the 1 -repetition maximum load for one month led to improvement in the six minute walking test, health related quality of life (HRQOL) and lower-limb muscle strength, without altering the levels of systemic inflammation ${ }^{38}$. Similarly, McFarlin et al. did not observe an improvement in inflammatory cytokine expression (IL-6 and TNF $\alpha$ ) in resistance-trained older women (65-80 years), compared to untrained controls after an acute bout of resistance exercise $^{39}$. The small sample sizes in both of these studies ( $n=6-10$ per treatment group) may have contributed to this null effect. Moreover, van Helvoort et al. conducted a study on sixteen COPD patients who performed a maximal incremental bicycle test and proved that COPD patients are exposed to systemic inflammation that is intensified by exhaustive exercise ${ }^{40}$. 
On the other side, Rosety-Rodriguez and colleagues in their study on young male adults with Down Syndrome for twenty-four years who were assigned to perform resistance circuit training with 6 stations, 3 days per week for 12 weeks. Exercise intensity was based on function of the 8 resistance maximum (RM) assessments proved that resistance circuit training improved low-grade systemic inflammation in male sedentary adults with Down syndrome ${ }^{41}$. Also, Nikseresht etal. conducted a 12 week study on middle-aged obese men and proved that aerobic interval training which consisted of running on a treadmill (4 sets of 4 minutes at $80-90 \%$ of maximal heart rate, with 3-minute recovery intervals) had better antiinflammatory effects (as indicated by the IL-10: TNF- $\alpha$ ratio) than nonlinear resistance training which consisted of 40-65 minutes of weight training at different intensities with flexible periodization ${ }^{42}$. While, Kohut etal. proved that aerobic exercise intervention, but not flexibility/resistance exercise, reduces serum inflammatory cytokines including interleukin-18 (IL-18), CRP and IL-6 among older adults; this reduction would be mediated, in part, by improvements in psychosocial factors and/or by $\beta$-adrenergic receptor mechanisms ${ }^{43}$.

The exact mechanisms by which physical activity may reduce inflammation are not entirely understood, there are some data pointing to factors that may contribute to an effect of repeated bouts of muscle contraction leading to improvements in inflammatory status over time ${ }^{44}$. Exercise training-induced improvements in inflammatory status may also result from the modulation of intracellular signaling pathways and cellular function that are mediated by nitric oxide (NO) and ROS ${ }^{45}$. Also, exercise training decreases mononuclear cell production of atherogenic cytokines (TNF $\alpha$ and IL-1 $\alpha$ ), while the production of atheroprotective cytokines (IL-10, IL-4, and transforming growth factor beta-1 (TGF $\beta 1)$ is increased ${ }^{46}$. Exercise training also reduces CD14+CD16+ monocyte number, as well as TNF- $\alpha$ production by monocytes ${ }^{47}$ and reduces monocyte cell-surface expression of toll-like receptor-4 (TLR4), a lipopolysaccharide (LPS) signaling receptor that likely contributes to attenuation of acute immune responses to infection or trauma ${ }^{48-50}$. Similarly, higher-intensity aerobic exercise training reduces stimulated production of TNF- $\alpha$ by monocytes. Thus, this data points to an adaptive down-regulation of cytokine release from innate immune cells in response to regularly performed muscu- lar contraction ${ }^{51,52}$. Moreover, the potential mechanisms for the anti-inflammatory effect of exercise may include reduced percentage of body fat and macrophage accumulation in adipose tissue, muscle-released interleukin- 6 inhibition of tumor necrosis factor-a, and the cholinergic anti-inflammatory pathway ${ }^{53}$. Finally, within the limit of this study, aerobic exercise is more appropriate for modulating inflammatory cytokine levels than resisted exercise training in patients with chronic obstructive pulmonary disease.

The current study has important strengths and limitations, the major strength is the supervised nature of the study in addition to the number of subjects in our study was relatively larger than those of previous studies in COPD. However, one of the limitations of this study is that the results were based on selection of participants with moderate degree COPD severity.

\section{Conclusion}

The current study provides evidence that aerobic exercise is more appropriate for modulating inflammatory cytokine levels than resisted exercise training in patients with chronic obstructive pulmonary disease.

\section{Acknowledgment}

This project was funded by the Deanship of Scientific Research (DSR), King Abdulaziz University, Jeddah, under grant no. (56/142/1434). The authors, therefore, acknowledge with thanks DSR technical and financial support.

\section{References}

1. Kochanek K, Xu J, Minino A. Deaths: preliminary data for 2009. National Center for Health Statistics, Hyattsville, MD, 2011.

2. NHLBI Morbidity and Mortality Chart book. Available at: http://www.nhlbi.nih.gov/resources/docs/chtbookhtm Accessed August 26, 2011.

3. Mathers C, Loncar D. Projections of global mortality and burden of disease from 2002 to 2030. PLoS Med 2006; 3: e442.

4. Rosenberg S, Kalhan R. Biomarkers in chronic obstructive pulmonary disease. Translational Research 2012; 159(4):228-237.

5. Chen H, Wang Y, Bai C, Wang X. Alterations of plasma inflammatory biomarkers in the healthy and chronic 
obstructive pulmonary disease patients with or without acute exacerbation. Journal of Proteomics 2012; 75(10): 2835-2843.

6. Sin D, Man S. Why are patients with chronic obstructive pulmonary disease at increased risk of cardiovascular diseases? The potential role of systemic inflammation in chronic obstructive pulmonary disease. Circulation 2003; 107: 1514-1519.

7. Schols A, Buurman W, van den Brekel A, Dentener M, Wouters E. Evidence for a relation between metabolic derangements and increased levels of inflammatory mediators in a subgroup of patients with chronic obstructive pulmonary disease. Thorax 1996; 51:819-824.

8. De Godoy I, Donahoe M, Calhoun W, Mancino J, Rogers R. Elevated TNF- $\alpha$ production by peripheral blood monocytes of weight-losing COPD patients. Am J Respir Crit Care Med 1996; 153: 633-637.

9. Angerio A. Chronic obstructive pulmonary disease and cytokines. Crit Care Nurs Q 2008; 31: 321-323.

10. Schneider A, Dinant G, Maag I, Gantner L, Meyer J, Szecsenyi J. The added value of C-reactive protein to clinical signs and symptoms in patients with obstructive airway disease: results of a diagnostic study in primary care. BMC Fam Pract 2006; 7: 28.

11. Bernard S, LeBlanc P, Whittom F, Carrier G, Jobin J, Belleau R. Peripheral muscle weakness in patients with chronic obstructive pulmonary disease. Am J Respir Crit Care Med 1998; 158 (2): 629-634.

12. Karadag F., Kirdar S., Karul A. and Ceylan E. (2008): The value of C-reactive protein as a marker of systemic inflammation in stable chronic obstructive pulmonary disease. European Journal of Internal Medicine, 19(2): 104108.

13. Decramer M. Pulmonary rehabilitation 2007: from bench to practice and back. Clin Invest Med 2008; 31: 312318.

14. van Helvoort H, van de Pol M, Heijdra Y, Dekhuijzen P. Systemic inflammatory response to exhaustive exercise in patients with chronic obstructive pulmonary disease. Respiratory Medicine 2005; 99(12):1555-1567.

15. Rochester C. Exercise training in chronic obstructive pulmonary disease. J Rehabil Res Dev 2003; 40 (5 Suppl. 2): 59-80.

16. Lacasse Y, Maltais F, Goldstein R. Pulmonary rehabilitation: an integral part of the long-term management of COPD. Swiss Med Wkly 2004; 134: 601- 605.
17. Pedersen B, Hoffman-Goetz L. Exercise and the immune system: regulation, integration, and adaptation. Physiol Rev 2000; 80 (3): 1055-1081

18. Tirakitsoontorn P, Nussbaum E, Moser C, Hill M, Cooper D. Fitness, acute exercise, and anabolic and catabolic mediators in cystic fibrosis. Am J Respir Crit Care Med 2011; 164 (8 Pt 1): 1432-1437.

19. Tanaka H, Monahan K, Seals D. Age-predicted maximal heart rate revisited. J Am Coll Cardiol 2001; 37: 153156.

20. ACSM (American College of Sports Medicine). Position stand: progression models in resistance training for healthy adults. Med Sci Sports Exerc 2002; 34: 364-380.

21. Pauwels R, Buist A, Calverley P, Jenkins C, Hurd S. Global strategy for the diagnosis, management, and prevention of chronic obstructive pulmonary disease. Am J Respir Crit Care Med 2012; 163:1256-1276.

22. Deng Z, Zhao P, Cao C, Sun S, Zhao F, Lu C, Ma H. C-reactive protein as a prognostic marker in chronic obstructive pulmonary disease. Exp Ther Med 2014; 7: 443-446.

23. Chen H, Wang D, Bai C,Wang X. Proteomics-based biomarkers in chronic obstructive pulmonary disease. $J$ Proteome Res 2010; 9:2798-808.

24. Fattouh M, Alkady O. Inflammatory biomarkers in chronic obstructive pulmonary disease. Egyptian Journal of Chest Diseases and Tuberculosis 2014; 63: 799-804.

25. Broekhuizen R, Wouters E, Creutzberg E, Schols A. Raised CRP levels mark metabolic and functional impairment in advanced COPD. Thorax 2006; 61:17e22.

26. Dekker M, Lee S, Hudson R, Kilpatrick K, Graham $T$, Ross R.An exercise intervention without weight loss decreases circulating interleukin-6 in lean and obese men with and without type 2 diabetes mellitus. Metabolism 2007; 56(3):332-8.

27. Mikkelsen U, Couppé C, Karlsen A, Grosset J, Schjerling P, Mackey A, Klausen H, Magnusson S, Kjær M. Lifelong endurance exercise in humans: circulating levels of inflammatory markers and leg muscle size. Mech Ageing Dev 2013;134(11-12):531-40.

28. Sugawara K, Takahashi H, Kashiwagura T, Yamada K, Yanagida S, Homma M, Dairiki K, Sasaki H, Kawagoshi A, Satake M, Shioya T. Effect of anti-inflammatory supplementation with whey peptide and exercise therapy in patients with COPD. Respiratory Medicine 2012; 106: $1526 \mathrm{e} 1534$ 
29. You T, Berman D, Ryan A, Nicklas B. Effects of hypocaloric diet and exercise training on inflammation and adipocyte lipolysis in obese postmenopausal women. $J$ Clin Endocrinol Metab 2004; 89(4):1739-46.

30. Larsen A, Aukrust P, Aarsland T, Dickstein K. Effect of aerobic exercise training on plasma levels of tumor necrosis factor alpha in patients with heart failure. $A m \mathrm{~J}$ Cardiol 2001; 88(7):805-8.

31. Giannopoulou I, Fernhall B, Carhart R, Weinstock R, Baynard T, Figueroa A, Kanaley J. Effects of diet and/or exercise on the adipocytokine and inflammatory cytokine levels of postmenopausal women with type 2 diabetes. Metabolism 2005; 54:866-75.

32. Troseid M, Lappegard KT, Mollnes T, Arnesen H, Seljeflot I. The effect of exercise on serum levels of interleukin-18 and components of the metabolic syndrome. Metab Syndr Relat Disord 2009;7(6):579-84.

33. Lakka T, Lakka H, Rankinen T, Leon A, Rao D, Skinner J, Wilmore J, Bouchard C. Effect of exercise training on plasma levels of C-reactive protein in healthy adults: the HERITAGE Family Study. Eur Heart J 2005; 26:2018-25.

34. Rosa N, Lira F, Oyama L, Zanchi N, Yamashita A, Batista M, Oller do Nascimento C, Seelaender M. Exhaustive exercise causes an anti-inflammatory effect in skeletal muscle and a pro-inflammatory effect in adipose tissue in rats, Eur J Appl Physiol 2009; 106: 697-704 PubMed.

35. Balducci S, S. Zanuso A, Nicolucci F, Fernando S, Cavallo $\mathrm{P}$, Cardelli S. Antiinflammatory effect of exercise training in subjects with type 2 diabetes and the metabolic syndrome is dependent on exercise modalities and independent of weight loss. Nutrition, Metabolism and Cardiovascular Diseases 2010; 20: 608-617.

36. Brooks N, Layne J, Gordon P, Roubenoff R, Nelson M, Castaneda-Sceppa C. Strength training improves muscle quality and insulin sensitivity in Hispanic older adults with type 2 diabetes. Int J Med Sci 2007; 4:19-27.

37. Rall L, Roubenoff R, Cannon J, Abad L, Dinarello C, Meydani S. Effects of progressive resistance training on immune response in aging and chronic inflammation. Med Sci Sports Exerc 1996; 28:1356-65.

38. Rodrigo C., Celso R. , Carvalho C. Impact of Resistance Training in Chronic Obstructive Pulmonary Disease Patients during Periods of Acute Exacerbation. Archives of Physical Medicine and Rehabilitation 2014; 95(9):1638-1645.
39. McFarlin B, Flynn M, Campbell W, Stewart L, Timmerman K. TLR4 is lower in resistance-trained older women andrelated to inflammatory cytokines. Med Sci Sports Exerc 2004; 36:1876-83.

40. van Helvoort H, van de Pol M, Heijdra Y, Dekhuijzen P. Systemic inflammatory response to exhaustive exercise in patients with chronic obstructive pulmonary disease. Respir Med 2005; 99(12):1555-67.

41. Rosety-Rodriguez M, Camacho A, Rosety I, Fornieles G, Rosety MA, Diaz AJ, Rosety M, Ordonez FJ. Resistance circuit training reduced inflammatory cytokines in a cohort of male adults with Down syndrome. Med Sci Monit 2013; 19:949-53 PubMed.

42. Nikseresht M, Agha-Alinejad H, Azarbayjani MA, Ebrahim K. Effects of nonlinear resistance and aerobic interval training on cytokines and insulin resistance in sedentary men who are obese. J Strength Cond Res 2014; 28(9):2560-8.

43. Kohut M, McCann D, Russell D, Konopka D, Cunnick J, Franke W, Castillo M, Reighard A, Vanderah E. Aerobic exercise, but not flexibility/ resistance exercise, reduces serum IL -18, CRP and IL-6 independent of beta-blockers, BMI and psychosocial factors in older adults. Brain Behav Immun 2006; 20(3):201-9.

44. Beavers K, Brinkley T, Nicklas B. Effect of exercise training on chronic inflammation. Clin Chim Acta 2010; 411(11-12):785-93.

45. Scheele C, Nielsen S, Pedersen B. ROS and myokines promote muscle adaptation to exercise. Trends Endocrinol Metab 2009; 20:95-9.

46. Smith J, Dykes R, Douglas J, Krishnaswamy G, Berk $\mathrm{S}$. Long-term exercise and atherogenic activity of blood mononuclear cells in persons at risk of developing ischemic heart disease. JAMA 1999; 281:1722-7.

47. Timmerman K, Flynn M, Coen P, Markofski M, Pence B. Exercise training induced lowering of inflammatory (CD14+CD16+) monocytes: a role in the anti-inflammatory influence of exercise? J Lenkoc Biol 2008; 84:1271-8. 48. Stewart L, Flynn M, Campbell W, Craig B, Robinson J, McFarlin B, Timmerman K, Coen P, Felker J, Talbert E. Influence of exercise training and age on CD14+ cellsurface expression of toll-like receptor 2 and 4 . Brain Behav Immun 2005; 19:389-97.

49. Apolzan J, Flynn M, McFarlin B, Campbell W. Physical activity status, but not age, influences inflammatory biomarkers and toll-like receptor 4. J Gerontol A Biol Sci Med Sci 2006; 61:388-93. 
50. Gleeson M, McFarlin B, Flynn M. Exercise and tolllike receptors. Exerc Immunol Rev 2006; 12:34-53.

51. Sloan R, Shapiro P, Demeersman R, McKinley P, Tracey K, Slavov I, Fang Y, Flood P. Aerobic exercise attenuates inducible TNF production in humans. J Appl Physiol 2007; 103:1007-11.
52. Garrod R, Ansley P, Canavan J, Jewell A. Exercise and the inflammatory response in chronic obstructive pulmonary disease (COPD)--Does training confer antiinflammatory properties in COPD?. Med Hypotheses 2007; 68(2):291-8.

53. Woods J, Vieira V, Keylock K.Exercise, inflammation, and innate immunity. Neurol Clin 2006; 24(3):585-99. 